\title{
The effect of different pre-reading activities on pre-intermediate and advanced EFL students' reading comprehension
}

\author{
O efeito de diferentes atividades de pré-leitura na compreensão leitora \\ de alunos dos níveis pré-intermediário e avançado de inglês como \\ língua estrangeira
}

\author{
Tatiana Koerich Rondon ${ }^{1}$ \\ Lêda Maria Braga Tomitch ${ }^{2}$
}

\begin{abstract}
This study aimed at investigating the effects of two pre-reading activities, namely Contextual Redefinition and Graphic Organizer, on the reading comprehension of preintermediate and advanced Brazilian EFL students. Based on Schema Theory (RUMELHART, 1980; ANDERSON; PEARSON, 1998), both pre-reading activities were expected to have a positive effect on students' reading comprehension. Using a repeated-measures design, participants' reading comprehension was tested via written free recall and comprehension questions. Quantitative analysis revealed that treatment with the pre-reading activity Contextual Redefinition weakened pre-intermediate students' reading comprehension. Contrastingly, it had a positive effect on advanced students' reading comprehension as measured by comprehension questions. In turn, the Graphic Organizer had a positive effect on pre-intermediate students' reading comprehension whereas it decreased advanced students' reading comprehension as measured by written free recall and had no effect when measured by comprehension questions.
\end{abstract}

Keywords: Reading. Schema Theory. Pre-reading Activities.

Resumo: O objetivo deste estudo foi investigar os efeitos das atividades de pré-leitura Redefinição Contextual e Organizador Gráfico na compreensão leitora de alunos brasileiros de inglês dos níveis pré-intermediário e avançado. Com base na Teoria dos Esquemas (RUMELHART, 1980; ANDERSON; PEARSON, 1998), esperava-se que ambas as atividades tivessem um efeito positivo na compreensão leitora dos alunos. Através de medidas repetidas, a compreensão dos alunos foi testada por meio da evocação do conteúdo lido e de perguntas de compreensão. A análise quantitativa revelou que o tratamento com a atividade Redefinição Contextual enfraqueceu a compreensão dos alunos pré-intermediários. Por outro lado, teve um efeito positivo na compreensão leitora dos alunos avançados quando medida por questões de compreensão. Por sua vez, a atividade Organizador Gráfico teve um efeito positivo na compreensão dos alunos pré-intermediários, ao passo que diminuiu a compreensão leitora dos alunos avançados quando medida por evocação do conteúdo lido e não surtiu nenhum efeito quando medida por questões de compreensão.

Palavras-chave: Leitura. Teoria dos Esquemas. Atividades de Pré-leitura.

\footnotetext{
${ }^{1}$ Universidade Federal de Santa Catarina, Centro de Comunicação e Expressão, Departamento de Letras e Literaturas Estrangeiras, Programa de Pós-Graduação em Inglês: Estudos Linguísticos e Literários, Florianópolis, SC, Brasil. Endereço eletrônico: tatiana.rondon@ posgrad.ufsc.br.

${ }^{2}$ Universidade Federal de Santa Catarina, Centro de Comunicação e Expressão, Departamento de Letras e Literaturas Estrangeiras, Programa de Pós-Graduação em Inglês: Estudos Linguísticos e Literários, Florianópolis, SC, Brasil. Endereço eletrônico: leda@cce.ufsc.br.
} 


\section{Introduction}

When people start reading in their first language, they most likely have no awareness of the cognitive processes that are necessary to carry out this activity (AEBERSOLD; FIELD, 1997). The challenges faced by readers who are taking their first steps tend to be forgotten once they become more proficient in reading. Irrespective of the language, be it the reader's native language or a foreign one, to read a text, one needs to know its topic, its underlying structure, its language, its cultural aspects, amongst other aspects (DAVIES, 1995; AEBERSOLD; FIELD, 1997). Because of that, teachers should attempt to understand the processes involved in reading and find ways to observe how these processes take place so that they can plan reading lessons according to their students' needs, fostering the development of their reading ability (DAVIES, 1995).

When working with reading in the classroom, teachers should not simply tell students to read the text and be prepared to answer questions about it; instead, they should provide students with guidance, which means providing pre-reading, while reading, and post-reading activities that prepare students to read a text and help them remember the information it contains (MOORE; READENCE; RICKELMAN, 1999). The pre-reading stage is considered one of the most important parts of the reading lesson, especially for English as a Foreign Language $\left(\mathrm{EFL}^{3}\right)$ students (MAUNSELL, 2019). Pre-reading activities can help readers get familiarized with texts through work on vocabulary contained in a specific reading passage (JAHANGARD; MOINZADEH; KARIMI, 2011; AZIZIFAR et al., 2015; MOGHADDAM; MAHMOUDI, 2016), making predictions about the content of the passage (TOMITCH, 1991; HUDSON, 1998) and associations with the topic of the passage (ALIPAHANI; MAHMOUDI, 2014; AZIZIFAR et al., 2015; HASHEMI; MOBINI; KARIMKHANLOOIE, 2016), among others. Each pre-reading activity may have different degrees of effectiveness depending on the linguistic proficiency of the student (CARRELL, 1998; HUDSON, 1998). Thus, the present study is concerned with the question: how do different pre-reading activities influence students at different levels of proficiency?

This article reports on the results of part of the first author's master thesis research under the supervision of the second author. Besides investigating the effects of different pre-reading activities on Brazilian EFL students' reading comprehension, the aforementioned master's thesis research also sought to investigate whether there was a correlation between students' working memory capacity and their performance in the comprehension tests in each of the pre-

\footnotetext{
${ }^{3}$ In this article, the terms second and foreign language will be used interchangeably.
} 
reading activities conditions. For the sake of conciseness, the authors decided to present the results separately. In terms of organization, this article is divided as follows: this introduction; review of literature; method; results and discussion; and final remarks.

\section{Review of Literature}

Pre-reading activities have been used as tools to aid students in constructing meaning from text, whether it is in one's native language or a foreign language. When reading in a foreign language, besides encountering unfamiliar topics, students have to deal with unfamiliar terms and styles of writing that are, as a consequence, unusual to them (MOORE; READENCE; RICKELMAN, 1999). In the field of reading research, it is generally accepted that pre-reading activities have a positive effect on reading comprehension (ALIPANAHI; MAHMOUDI, 2014; AZIZIFAR et al., 2015; HASHEMI; MOBINI; KARIMKHANLOOIE, 2016).

To investigate the effects of two pre-reading activities, namely, pre-teaching vocabulary and pre-questioning, Alipanahi and Mahmoudi (2014) conducted a quasi-experimental study with second-grade high school students from four different groups in Iran. From this pool of one hundred students, sixty of them were chosen based on their scores on The Nelson English Test. After ensuring participants had similar language proficiency, they were randomly assigned to either the control or the experimental group. Three texts were taken from the students' textbook and a test with around 30 multiple-choice items was designed for each one. The experimental group received treatment with pre-vocabulary and pre-questioning reading strategies before reading the texts while the control group only read the texts. After reading, participants had forty minutes to answer the multiple-choice items. Results indicated that the experimental group did significantly better in the tests. However, it was not clear what steps were followed in the pre-reading activities used. Furthermore, even though the researchers mentioned that participants had a similar level of proficiency, it was not clear whether they were beginners, intermediate or advanced students of EFL.

A similar study was conducted by Azizifar et al. (2015), who used the same pre-reading activities in an experiment with sixty female Iranian high-school students. Participants were assigned to two experimental groups based on the results of the Michigan Test, which served as the pre-test/post-test. The treatment was implemented during participants' regular classes for a period of five weeks with a total of 10 sessions of sixty minutes. Each session started with a pre-reading treatment which lasted for about ten minutes. After that, participants read the texts individually and answered a set of comprehension items related to explicit and implicit information presented in the texts. The researchers found that both groups did significantly 
better in the post-test. Furthermore, participants who received treatment with pre-questioning did significantly better than the group in the vocabulary condition. Our interpretation is that in the treatment with vocabulary, researchers presented keywords and their definitions, as well as translations, which usually leads to a superficial level of processing. Pre-questioning, on the other hand, which focuses on the content of the text, might lead to a deeper level of processing, enabling participants to perform better in the comprehension test. Also, even though participants' proficiency was controlled using the Michigan Test, their level was not mentioned.

In a more comprehensive study, Hashemi, Mobini, and Karimkhanlooie (2016) investigated the effect of three different pre-reading activities on the reading comprehension of EFL Iranian high school students. One hundred and twenty-five participants were distributed among three experimental groups and one control group. The treatments consisted of prequestioning, brainstorming, and the pre-rereading strategy known as KWL, which stands for what I know, want to know, and learned. The design of the study was a pre-test/post-test in which the pre-test was also intended to ensure participants had similar proficiency. Results showed that all treatments significantly improved participants' reading comprehension when compared to the control group. Furthermore, the KWL treatment was the most effective of the three, differently from the previous study in which pre-questioning was the most effective one. Considering that the three studies mentioned so far had a similar target population (ALIPANAHI; MAHMOUDI, 2014; AZIZIFAR et al., 2015; HASHEMI; MOBINI; KARIMKHANLOOIE, 2016), the different effects of the pre-reading activities might be attributed to participants' proficiency. As previously mentioned, proficiency was controlled in all three studies. However, it was not clear whether participants in the three studies belonged to the same level. As important as it is, there is still little research in the area investigating the possible effects of different kinds of pre-reading activities on various levels of proficiency (HUDSON, 1998; MIHARA, 2011).

Aiming to investigate the role played by schemata in second language (L2) reading by adult English as a Second Language (ESL) students, Hudson (1998) experimented with three proficiency levels: beginning, intermediate and advanced. He examined the effects of three types of treatment: pre-reading (PRE), vocabulary (VOC), and read-test/read-test (RT) on the reading comprehension of ninety-three ESL students. Results showed that different types of intervention were effective at different levels of proficiency. For the advanced level of proficiency, the most effective treatment was the RT, while the PRE and VOC treatments showed no significant difference. The author argued that participants from the advanced level might have applied skills that were not available to beginning and intermediate levels due to a 
threshold in linguistic knowledge. For the beginning and intermediate level participants, the PRE treatment was more effective than the VOC and the RT. The researcher explained that the treatment with the pre-reading activity may have compensated for their lack of linguistic knowledge. He concluded that more research is needed to establish which type of pre-reading activity is more useful for each level of proficiency.

In a more recent study, Mihara (2011) investigated the effects of two pre-reading activities, vocabulary pre-teaching and pre-questioning on the reading comprehension of seventy-eight Japanese EFL students across two levels of proficiency, pre-intermediate and upper-intermediate as defined by their results on the TOEIC ${ }^{4}$. It is worth mentioning that the treatment with vocabulary encouraged surface-level processing: participants received a list of words and phrases in English that were important to the overall meaning of the texts and they were required to translate them to Japanese. After doing this individually, the researcher would present the meanings of the words and participants had to check their answers. In the treatment with pre-questioning, participants received the list of comprehension questions that appeared after each text in their textbooks to answer before reading. The measures of comprehension used were true/false items and comprehension questions. Just as with Azizifar et al.'s study (2015) reported previously, results showed that the pre-reading activity that involved prequestioning had a greater impact on participants' comprehension from both levels of proficiency: pre-intermediate and upper-intermediate. However, the author also reported that participants had the impression that they learned more from the pre-reading activity that aimed at pre-teaching vocabulary, especially participants from the upper-intermediate level of proficiency.

As mentioned previously, the present study is aimed at investigating the effects of two pre-reading activities, namely Contextual Redefinition and Graphic Organizer (MOORE; READENCE; RICKELMAN, 1999) on pre-intermediate and advanced Brazilian EFL students' reading comprehension. The Contextual Redefinition was intended to provide participants with relevant vocabulary items for the understanding of the texts' main ideas. The rationale was that, by guessing the meanings of the words based on their prior knowledge and context clues, readers would be able to process the words more deeply than in the previously mentioned studies (MIHARA, 2011; AZIZIFAR et al., 2015). Thus, the Contextual Redefinition was expected to positively affect reading comprehension. Moreover, it was expected to have a greater effect on pre-intermediate than on advanced EFL students' reading comprehension

\footnotetext{
${ }^{4}$ TOEIC stands for Test of English for International Communication. It is a standardized English proficiency test.
} 
when measured by comprehension questions. Because pre-intermediate students are closer to the language threshold (CLARKE, 1998), it was expected that knowledge of vocabulary could help them understand specific information in the text, tackled by comprehension questions.

In turn, the objective of the Graphic Organizer was to preview the texts' main ideas through their structure. It was also expected to have a positive effect on both pre-intermediate and advanced EFL students' reading comprehension. Furthermore, it was expected to have a greater effect on advanced than on pre-intermediate EFL students' reading comprehension as measured by written free recall. This was expected because advanced students are more likely to use skills that are not available to the pre-intermediate level (HUDSON, 1998). Thus, they would benefit more from knowing how the texts were organized whereas pre-intermediate students might still need to reconcile with the unknown vocabulary present in the text.

\section{Objectives and Research Questions}

The objective of the present study was to investigate the effects of two pre-reading activities, Contextual Redefinition and the Graphic Organizer (MOORE; READANCE; RICKELMAN, 1999), on the reading comprehension of pre-intermediate and advanced Brazilian EFL students. Following the stated objective, this study sought to answer the following research questions:

a. Do the pre-reading activities Contextual Redefinition and Graphic Organizer influence pre-intermediate and advanced EFL students' reading comprehension as measured by written free recall?

b. Do the pre-reading activities Contextual Redefinition and Graphic Organizer influence pre-intermediate and advanced EFL students' reading comprehension as measured by comprehension questions?

\section{Groups and Participants}

Forty-six teenage and adult students from seven different EFL groups in a private institute in Brazil were invited to participate in this quasi-experimental field study. All participants provided written informed consent before data collection, as well as underage participants' legal guardians. Out of the forty-five students who agreed to participate, thirty students who had been present in both data collection encounters were selected based on their reading proficiency, fifteen for each level. The test used was comprised of the reading section of a multiple-choice placement test from the book Passages published by Cambridge, which is in accordance with participants' course materials. An independent measures t-test confirmed 
that the pre-intermediate and advanced groups were different in terms of proficiency $(t(28)=$ 11.07; $\mathrm{p}<.001)$. The results were interpreted taking into consideration the Common European Framework of Reference (CEFR). Hence, participants at the B1 level of proficiency were included in the pre-intermediate group, and participants at the $\mathrm{C} 1$ level of proficiency constituted the advanced group.

Given the natural school context of the study, participants' age range (whole group) was between 12 and 66 years old $(\mathrm{N}=30, \mathrm{M}=32.33, \mathrm{SD}=19.43)$. In the pre-intermediate group, participants ranged from 12 to 66 years old $(\mathrm{N}=15, \mathrm{M}=29.12, \mathrm{SD}=19.17)$, whereas in the advanced group, the age range was from 12 to 64 years old $(\mathrm{N}=15, \mathrm{M}=35.53, \mathrm{SD}=19.81)$. An independent measures t-test confirmed that the pre-intermediate and advanced groups were similar in terms of age $(t(28)=0.90 ; \mathrm{p}=.38)$. There were 8 female and 7 male participants in the pre-intermediate group, whereas there were 9 female and 6 male participants in the advanced group. Participants answered a profile questionnaire in their native language regarding their studying history and reading habits. Participants in the advanced group had been studying English longer than the ones in the pre-intermediate group and they were more exposed to English outside the classroom. The advanced participants also reported reading more frequently outside the classroom than the ones in the pre-intermediate group.

\section{Materials}

The stimuli used in this study were six texts selected from the webpage of the British Council $^{5}$. Three texts were selected for the pre-intermediate group (B1): Digital Habits Across Generations (432 words), The Legend of Fairies (387 words), and Robot Teachers (346 words). For the advanced group (C1), the selected texts were entitled: Do you have the right mindset? (462 words), Me and My Brain (472 words), and The Rise of Fake News (466 words). It is worth mentioning that the selected texts are categorized as appropriate to B1 and C1 levels of the CEFR on the website of the British Council. These texts were chosen because they had a comparable number of words, they fit one page, and they were expository texts with a clear textual structure.

For the pre-reading activity Contextual Redefinition, the materials were ten unfamiliar words selected from each text, a sentence that provided context clues to the meaning of the selected words, and a list of dictionary entries of those words. For the pre-reading activity Graphic Organizer, the materials were diagrams with the main ideas of the texts structured

\footnotetext{
5 The British Council is an international organization of the United Kingdom for cultural relations and educational opportunities. https://www.britishcouncil.org.
} 
according to their textual organizational pattern. Six comprehension questions, written in Brazilian Portuguese, that targeted textually explicit information were created for each text. The questions were chosen based on the feedback provided by three independent raters to ensure participants had to read the texts to answer them. Finally, three retrospective questionnaires were created, with questions in Portuguese - participants' native language - about the texts, the pre-reading activities, the written free recall task, the comprehension questions as well as their judgment regarding the level of difficulty of the texts.

\section{Data Collection}

Data collection was divided into five parts to be carried out in two encounters with participants during their regular English classes. During the first encounter, in the first part of data collection, participants answered the profile questionnaire, which took approximately ten minutes. In the second part, participants had a maximum of twenty minutes to take the reading proficiency test. They were informed they could not ask questions regarding the content of the texts being read or any other question that could help them understand the texts. These procedures were repeated with all the seven groups that accepted to participate in this research.

During the second encounter, in the third part of data collection (control condition), participants were required to read a text that was appropriate to their proficiency level for approximately ten to twelve minutes. Participants were instructed to read the text to understand its main idea and remember as much information as possible. After that, the texts were collected, and participants had about five minutes to do a written free recall task. They received a sheet of paper and were instructed to write everything they recalled from the text, in Portuguese, using complete sentences. Then, this sheet of paper was collected, and participants received a set of six comprehension questions in Portuguese about the text. They had about five to seven minutes to answer the questions in that same language. After that, the questions were collected, and participants received a retrospective questionnaire to complete in another five minutes. In total, the third part of the data collection had approximately thirty minutes of duration.

In the fourth and fifth parts, participants received the treatments with the pre-reading activities Contextual Redefinition and Graphic Organizer respectively. For the treatment with the pre-reading activity Contextual Redefinition (Treatment 1), participants were presented with the unknown words extracted from the text beforehand, for instance, the word prune. These words were presented in isolation on a computer screen with a PowerPoint presentation and participants attempted to guess their meanings. Then, participants were presented with the 
words in the sentences with context clues and, again, they tried to guess the meanings of the words, this time basing their guesses on the context provided by the sentences, for example: "We have to prune our apple tree. It is getting too big". Finally, participants received a list with the meanings of the words in dictionary entries so that they could check their guesses, such as: "to cut off branches from a tree, bush, or plant, especially so that it will grow better in the future". This procedure took about three to five minutes, depending on the groups of participants. After the treatment, participants were required to do the same tasks that were presented in the control condition.

During the fifth and last part of data collection, for the treatment with the pre-reading activity Graphic Organizer (Treatment 2), participants were shown a diagram using a PowerPoint presentation with a representation of the rhetoric organization of the text and its main ideas. The ideas were presented one by one along with an explanation of how the text was structured as a way to establish a relationship among them. Again, this procedure took about three to five minutes, depending on the groups of participants. After the treatment, participants were required to do the same tasks that were presented in the control condition. In total, the second encounter with participants had approximately one hour and thirty minutes of duration. The procedures described for the second encounter of data collection were repeated with all the seven groups that accepted to participate in the present study. It is important to highlight that, to avoid order effects, the texts and activities used in the third, fourth, and fifth parts of data collection were counterbalanced.

\section{Data Analysis}

The written free recall was analyzed in terms of the number of propositional units remembered by each participant using a method developed by Tomitch (1990), which consists of identifying the "central proposition or propositions in each sentence and then the modifiers or attributes which modify the central proposition" (TOMITCH, 2003, p. 62). To score the comprehension questions, an answer key was created where each correct answer was subdivided into six main elements that made up a complete answer. For each element, participants received a 0.5 point. Therefore, participants' scores for each question could range from 0 to 3 points. Moreover, because the objective of the questions was to test comprehension, grammatical mistakes were disregarded (ROSCIOLI, 2017).

The normality of the data was assessed visually through histograms, box plots, and QQ plots, and further verified by tests of normality. It was found that pre-intermediate participants' scores for the comprehension questions after the treatment with the pre-reading 
activity Graphic Organizer had a bimodal distribution. However, no outliers were found. For the advanced group, analysis of box plots revealed two outliers for the free recall control condition variable and one outlier for the comprehension questions control condition variable. Because of the small number of participants, the outliers were not excluded from the analysis.

\section{Results and Discussion}

Results of the written free recall indicated that, for the pre-intermediate group, the highest mean score was for the condition in which participants received treatment with the prereading activity Graphic Organizer $(M=14.6)$, followed by the control condition $(M=14.53)$ and the treatment condition with the pre-reading activity Contextual Redefinition $(M=11.93)$. As for the advanced group, the highest mean score was for the control condition $(M=23.6)$, followed by the treatment with the pre-reading activity Contextual Redefinition $(M=22.93)$, and the treatment condition with the pre-reading activity Graphic Organizer $(M=19.66)$.

A two-way 2 (Group: pre-intermediate or advanced) x 3 (Condition: Treatment 1, Treatment 2, or Control) mixed ANOVA with repeated measures was conducted on written free recall scores. The results revealed no significant main effect of condition $(F(2,56)=8.63, \mathrm{p}>$ $\left..05, \eta p^{2}=.030\right)$ as well as no significant interaction between Group and Condition $(F(2,56)=$ $1.825, p>.05, \eta p^{2}=.061$ ), which could indicate that this measure of comprehension was not very appropriate to investigate the effects of the pre-reading activities. One possible reason is that participants deviated their attention from what they had comprehended to the writing task at hand, which involved more than just having understood the ideas in the text. Figure 1 shows the estimated marginal means for the three conditions.

Figure 1 - Estimated marginal means for written free recall

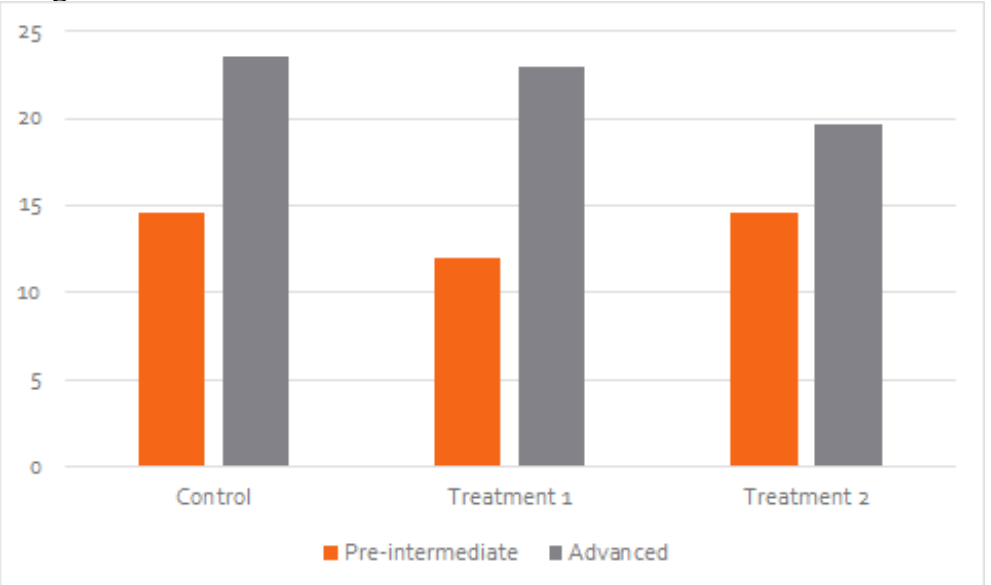

Source: elaborated by the author (2020). 
Even though statistical significance was not reached, some speculations can be made based on the raw scores of the written free recall task. The treatment with the pre-reading activity Graphic Organizer had a slight positive effect on pre-intermediate participants' comprehension, whereas the treatment with the pre-reading activity Contextual Redefinition decreased their comprehension. As for the advanced group, none of the two treatments affected comprehension positively. The treatment with the pre-reading activity Contextual Redefinition yielded an average score slightly below the control condition, whereas the treatment with the Graphic Organizer seems to have weakened participants' comprehension.

It was hypothesized that both pre-reading activities would affect pre-intermediate and advanced participants' comprehension positively. Based on the raw scores of the written free recall task, one might say that the pre-reading activity Contextual Redefinition weakened preintermediate participants' comprehension. One possible explanation for this result is related to the threshold hypothesis (CLARKE, 1998). As previously mentioned, for this task, participants had to write everything they remembered from the text using complete sentences. In other words, participants would have to be able to understand the idea units in the text to form a coherent textbase. For the advanced and fluent reader, this occurs automatically through effortless bottom-up processing. On the other hand, participants at the pre-intermediate level of proficiency still lack the linguistic knowledge that is necessary to engage in automatic bottomup processing, which can cause them to naturally employ top-down strategies when reading a text in a second language. This could explain why their means for the control condition and the treatment with the pre-reading activity Graphic Organizer were similar since the objective of this activity is to provide participants with a macrostructure of the text. As for the pre-reading activity Contextual Redefinition, it might have caused participants to avoid using top-down strategies by making them focus on the vocabulary items that were presented in the treatment. Hence, this might have overloaded their cognitive resources and led them to have difficulties in constructing coherent mental representations of the texts.

It was also expected that the treatment with the Graphic Organizer would have a greater impact on advanced participants' comprehension as measured by the written free recall. Based on the raw scores of this task, it could be said that this pre-reading activity weakened their comprehension. This result might be related to the nature of the propositional analysis and the effect of the pre-reading activity Graphic Organizer. Considering that the advanced participants have sufficient linguistic knowledge to be able to engage in automatic bottom-up processing, they are better able to understand the microstructure of the texts and construct a coherent mental representation. Given that the Graphic Organizer is meant to provide a macrostructure of the 
text, advanced participants might have gone from understanding both the micro and macrostructure of the text to building a situation model. In other words, with the aid of this prereading activity, they might have been able to integrate the information they extracted from the text with their previous knowledge. Contradictorily, for the written free recall task, in which participants had to write down everything they remembered from the text, participants may have forgotten part of the textual content while thinking about how they would write down this information.

Another possible explanation for this finding could be related to the type of organizational patterns of the texts chosen, which did not represent a challenge for the participants of this research. In a study conducted by Levine and Reves (1994), the authors claimed that the treatment with formal schemata yielded better results than content and linguistic schemata when participants read an argumentative text. Thus, it is possible that if advanced participants had encountered text types they were not accustomed to reading, they could have benefited from the pre-reading activity Graphic Organizer.

As for the results of the comprehension questions, for the pre-intermediate group, the highest mean score was for the condition in which they received treatment with the pre-reading activity Graphic Organizer $(M=4.26)$, followed by the control condition $(M=3.56)$ and the treatment condition with the pre-reading activity Contextual Redefinition $(\mathrm{M}=3)$. For the advanced group, the highest mean score was for the treatment condition with the pre-reading activity Contextual Redefinition $(\mathrm{M}=5.26)$, followed by the treatment condition Graphic Organizer and the control condition with the same mean score $(\mathrm{M}=4.06)$.

A two-way 2 (Group: pre-intermediate or advanced) x 3 (Condition: Treatment 1, Treatment 2, or Control) mixed ANOVA with repeated measures was conducted on comprehension questions scores. The results revealed a significant interaction between Group and Condition at the $5 \%$ level $(F(2,56)=4.411, p<.05)$ on comprehension questions scores. The Global Effect size using Partial Eta Squared was 0.136, which is a medium effect. The observed power was .738 , which is strong according to Cohen (1988). To investigate the significant interaction, simple effect tests were conducted using a Bonferroni correction. The effect of group at each condition presented only one pairwise effect for the Treatment 1 condition $(\mathrm{p}=.003)$, which indicates that the pre-reading activity Contextual Redefinition had a significant effect on advanced participants' reading comprehension as measured by comprehension questions when compared to the pre-intermediate group. Contrastingly, in the study conducted by Hudson (1998), the VOC treatment did not show a significant difference for the advanced participants. In Mihara's (2011) study, the pre-reading activity that worked 
with pre-questioning had a greater impact on participants' reading comprehension from both levels of proficiency when compared to vocabulary pre-teaching. Thus, to these researchers' knowledge, the present study is the first to find that pre-reading activities directed at vocabulary building might be beneficial to advanced students. However, the results should be interpreted carefully due to the small number of participants.

The results of the Two-Way Mixed ANOVA also revealed that the effect of condition at each group presented one pairwise effect approaching significance: Treatment 1 in relation to Treatment 2 for the Pre-intermediate group $(\mathrm{p}=.092)$. Figure 2 shows the estimated marginal means for the three conditions. Contrarily to what was hypothesized, the pre-reading activity Contextual Redefinition had a detrimental effect on pre-intermediate participants' reading comprehension while it had a positive effect on advanced participants when measured by comprehension questions. Other studies have shown that pre-reading activities involving vocabulary affect participants' reading comprehension positively, even though their effect is less pronounced when compared to other types of pre-reading activities (ALINAPAHI; MAHMOUDI, 2014; AZIZIFAR et al., 2015; MOGHADDAM; MAHMOUDI, 2016).

Figure 2 - Estimated marginal means for comprehension questions

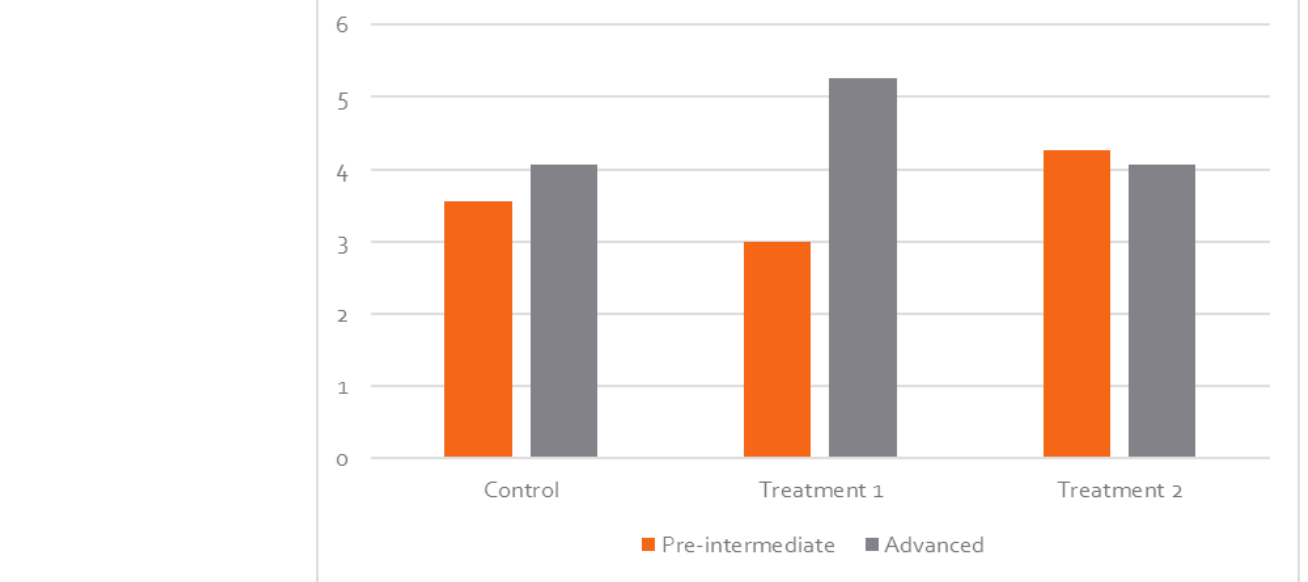

Source: elaborated by the author (2020).

In a study conducted by Tomitch (1991), the researcher used two pre-reading activities, one of them related to vocabulary pre-teaching (Possible Sentences) and the other was aimed at making predictions about the text (Request Procedure). She found that both pre-reading activities had a significant positive effect on intermediate participants' reading comprehension. Also, there were no significant differences between the two pre-reading activities. The prereading activity Possible Sentences had an element of guessing the content of the passage to be read similar to the pre-reading activity Request Procedure, which could explain why both of 
them had comparable effects. In the case of the present study, during the treatment with the prereading activity Contextual Redefinition, participants had to guess the meaning of the words in two moments: first, in isolation, and then using the context provided by sentences shown on a computer screen. This pre-reading activity did not include any step in which participants had to guess the content of the text to be read by connecting the words presented, which could have yielded different results.

Moreover, these findings could be explained by an interplay of factors. Text difficulty might have played a role because counterbalancing was done unevenly, due to the number of participants in each group. This happened because this is a quasi-experimental field study and, as such, data were collected during participants' regular English classes at the private school chosen for this study, following the natural configuration of participants' groups. Another factor that might have influenced the results is participants' previous knowledge of the content of the text. Even though the comprehension questions were pretested, participants' previous knowledge of the content of the texts might have helped them provide appropriate answers for the questions. Finally, it could also be that, although the words chosen to be part of the prereading activity Contextual Redefinition followed some specific criteria, they did not facilitate pre-intermediate participants' reading comprehension. In other words, this pre-reading activity did not allow pre-intermediate participants to process the meanings of the words in depth.

Concerning the pre-reading activity Graphic Organizer, even though statistical significance was not reached, some speculations can be made based on the raw scores of the comprehension questions. In this study, this pre-reading activity influenced pre-intermediate EFL students' reading comprehension positively. This was expected because pre-reading activities that assist readers in gaining awareness of text structure have had a positive effect on their reading comprehension (LEVINE; REVES, 1994; MOHAMMADI; MOENIKIA; ZAHED-BABELAN, 2010). This pre-reading activity might have allowed pre-intermediate participants to have a glimpse of the text to be read through the extracts showing the main ideas. Moreover, participants had to guess how the main ideas were connected in the remainder of the text. It could be said that the nature of this pre-reading activity is similar to the ones employed by Tomitch (1991) in the sense that participants were also allowed to read parts of the text beforehand. For the advanced group of EFL students, the Graphic Organizer had no effect when their reading comprehension was measured by comprehension questions. These results could be related to the findings of the Levine and Reves' study (1994), in which the authors found that content schemata and linguistic schemata are more effective in aiding advanced EFL students' reading comprehension. 


\section{Final Remarks}

The main objective of this study was to investigate the effects of the pre-reading activities Contextual Redefinition and Graphic Organizer on the reading comprehension of preintermediate and advanced Brazilian EFL students. It was expected that both pre-reading activities would have a positive effect on participants' reading comprehension as measured by written free recall and comprehension questions. More specifically, it was expected that the pre-reading activity Contextual Redefinition would be more beneficial to pre-intermediate participants than to advanced participants when their reading comprehension was measured by comprehension questions. Also, it was expected that the pre-reading activity Graphic Organizer would have a more positive impact on advanced participants' reading comprehension when compared to pre-intermediate participants' reading comprehension as measured by written free recall.

Contrary to expectations, the pre-reading activity Contextual Redefinition weakened pre-intermediate participants' reading comprehension as measured by both written free recall and comprehension questions. Also, the same pre-reading activity worsened advanced participants' reading comprehension as measured by written free recall. However, when reading comprehension was measured by comprehension questions, the pre-reading activity Contextual Redefinition had a positive impact on the advanced group. These findings contradict existing literature in the area which has found that pre-reading activities, in general, have a positive impact on reading comprehension (TOMITCH, 1991; LEVINE; REVES, 1994; HUDSON, 1998; MOHAMMADI; MOENIKIA; ZAHED-BABELAN， 2010; MIHARA， 2011; ALIPANAHI; MAHMOUDI, 2014; AZIZIFAR et al., 2015; HASHEMI; MOBINI; KARIMKHANLOOIE, 2016; MOGHADDAM; MAHMOUDI, 2016).

Even though the pre-reading activity Contextual Redefinition only had a positive effect on advanced participants' reading comprehension as measured by comprehension questions, both pre-intermediate and advanced participants' perception was positively affected by said pre-reading activity as revealed by the analysis of participants' comments in the retrospective questionnaires. This finding corroborates the results of Mihara's study (2011), in which participants had the impression they had learned more from the pre-reading activity that aimed at pre-teaching vocabulary.

The pre-reading activity Graphic Organizer decreased advanced participants' reading comprehension as measured by written free recall and had no effect when their reading comprehension was measured by comprehension questions, which was contrary to expectations. On the other hand, the same pre-reading activity had a positive effect on pre- 
intermediate participants' reading comprehension as measured by both written free recall and comprehension questions. As previously mentioned, this pre-reading activity might have helped pre-intermediate students to foresee the content of the texts to be read, which was beneficial to them similarly to the pre-reading activities employed by Tomitch (1991).

The results obtained through the pre-reading activity Graphic Organizer are coherent with participants' answers in the profile questionnaire. Regarding their reading habits, preintermediate participants reported trying to identify how a text is organized to understand it better more frequently than the advanced group. As previously mentioned, this could be explained if one considers that advanced students have better linguistic skills than preintermediate ones and, consequently, they rely less on top-down strategies to understand the message of the text.

Overall, the findings of the present study suggest that pre-reading activities have different effects on different levels of proficiency, which depend on other factors such as the measure of comprehension being used. It is important to point out that these results should be considered as suggestive rather than conclusive because of the nature of the present study. A series of factors could be improved and adapted to other contexts to investigate the matters described in this article. First, this research had a small number of participants, which was a total of thirty, equally distributed between the pre-intermediate and advanced groups. It is possible that, with a higher number of participants, the difference between the treatments employed in this study could have reached statistical significance. For future studies, it is recommended that a larger number of participants be recruited to increase validity.

Second, the reading proficiency test used to evaluate participants' reading comprehension ability might not have been appropriate to categorize them into the proficiency levels researched in the present study. Participants in the present study did not strictly correspond to the percentage of scoring for the pre-intermediate and advanced groups as determined by the Cambridge placement test, which was the basis for the reading proficiency test used. Thus, it is recommended that, for future research, other measures of evaluating participants' proficiency be used, such as TOEFL ${ }^{6}$ scores or participants' scores on the English test of $\operatorname{ENEM}^{7}$. Third, in the present study, participants' age had a very broad range, going from early teenagers to elderly people. The treatments with the pre-reading activities used in this study could have yielded different results if participants belonged to only one age group.

\footnotetext{
${ }^{6}$ TOEFL stands for Test of English as a Foreign Language. It is a standardized English proficiency test.

${ }^{7}$ ENEM stands for Exame Nacional do Ensino Médio, which is a standardized test used to admit students into Brazilian universities.
} 
Therefore, it is recommended that future studies attempt to focus on one age group as much as possible. Finally, other suggestions for further research can be made related to issues that were not part of the scope of the present study. As has been mentioned, different pre-reading activities can be investigated and how they affect EFL students at other levels of proficiency. Also, other types of study could be carried out such as longitudinal research that aims at developing students' reading comprehension through pre-reading activities, similar to the one conducted by Mohammadi, Moenikia, and Zahed-Babelan (2010).

Despite the limitations previously identified, it is believed that this study helped shed light into how pre-reading activities can affect EFL students' reading comprehension and how factors such as the type of pre-reading activity, students' level of proficiency, the type of text being read, and measures of reading comprehension are intertwined. In the case of the prereading activity Contextual Redefinition, which focused on vocabulary pre-teaching, it was clear that the steps involved in its preparation were not enough to provide pre-intermediate students with deep processing of the words so that they could incorporate them in their reading vocabulary. Also, the previously mentioned pre-reading activities might have posited an extra load on pre-intermediate students' processing demands. For these reasons, when EFL teachers choose pre-reading activities focused on vocabulary pre-teaching for pre-intermediate students, they should give preference to activities that work with vocabulary in an integrated way, that is, activities that relate the words presented with the text to be read. Moreover, teachers should choose pre-reading activities that are not teacher-centered, that is, activities that allow for preintermediate students to create their sentences with the words presented.

In the present study, while the pre-reading activity Contextual Redefinition did not have a positive effect on pre-intermediate EFL students' reading comprehension, it affected advanced EFL students' reading comprehension positively when it was measured by comprehension questions. It seems that for advanced students, the treatment with this prereading activity is enough for them to integrate the words presented with their reading vocabulary. As previously mentioned, in the study conducted by Hudson (1998), it was not possible to know whether advanced students benefitted from the treatment with vocabulary because the author did not use a control group. He did mention that advanced students benefitted more from the read/reread condition than the vocabulary condition. On the other hand, in the study conducted by Levine and Reves (1994), the authors pointed out that in the treatment they used to build vocabulary, they tried to isolate linguistic schemata from other types of schemata. They claimed that this treatment had a positive effect on advanced EFL students' reading comprehension. Considering what has been discussed, it seems that pre-reading activities that 
focus on vocabulary can be beneficial for advanced EFL students, if they provide context and allow students to relate the words/phrases to the texts to be read.

Concerning the pre-reading activity Graphic Organizer, which focuses on text organizational patterns, it seems to have a positive impact on pre-intermediate EFL students' reading comprehension as measured both by comprehension questions and written free recall. The preparation for this pre-reading activity involved selecting the main ideas of the texts and creating a diagram that reflected the organizational pattern of the text. The teacher/researcher would present each idea and ask students to try to identify how the ideas were related in the text to be read. The positive effect this procedure had on pre-intermediate EFL students' reading comprehension could be related to a decrease in the cognitive overload, the opposite of the effect caused by the pre-reading activity Contextual Redefinition. Taken together with the results of previous studies, it is possible to conclude that the pre-reading activities that are more appropriate for pre-intermediate EFL students have an element of forecasting the content of the text to be read. These pre-reading activities, which include the pre-reading activity Graphic Organizer used in the present study and the pre-reading activities Possible Sentences and Request Procedures employed by Tomitch (1991), allow students to predict what they will read through extracts carefully chosen by the researcher.

In turn, the pre-reading activity Graphic Organizer lessened advanced EFL students' reading comprehension as measured by written free recall and had no effect when their reading comprehension was measured by comprehension questions. It is possible that, for the advanced level, this pre-reading activity offered students information that they could get by just reading the text. Perhaps if the topic of the texts the advanced students had to read involved information about other cultures, the pre-reading activity Graphic Organizer could have had a positive effect on their reading comprehension. For this reason, teachers should have in mind that the prereading activity they choose needs to be adequate for the type of text to be read as well.

All things considered, the present study contributed with empirical evidence for the use of specific pre-reading activities with Brazilian EFL students from the pre-intermediate and advanced levels of proficiency. When teachers are planning their reading lessons and must choose appropriate pre-reading activities, they should bear in mind the level of proficiency of the students and how they should approach the text. 


\section{References}

AEBERSOLD, J. A.; FIELD, M. L. From reader to reading teacher. Cambridge: Cambridge University Press, 1997.

ALIPANAHI, F.; MAHMOUDI, R. Pre-reading Activities and Reading Comprehension. Advances In Environmental Biology, v. 11, n. 8, p. 742-747, jul. 2014.

ANDERSON, R. C.; PEARSON, D. P. A schema-theoretic view of basic processes in reading comprehension. In: CARRELL, P. L.; DEVINE, J.; ESKEY, D. E. Interactive approaches to second language reading. Cambridge: Cambridge University Press, 1998. p. 35-55.

AZIZIFAR, A.; ROSHANI, S.; GOWHARY, H.; JAMALINESARI, A. The Effect of Prereading Activities on the Reading Comprehension Performance of Ilami High School Students. Procedia: Social and Behavioral Sciences, n. 192, p. 188-194, jun. 2015.

CARRELL, P. L. Introduction: Interactive approaches to second language reading. In: CARRELL, P. L.; DEVINE, J.; ESKEY, D. E. Interactive approaches to second language reading. Cambridge: Cambridge University Press, 1998. p. 1-7.

CLARKE, M. A. The short circuit hypothesis of ESL reading - or when language competence interferes with reading performance. In: CARRELL, P. L.; DEVINE, J.; ESKEY, D. E. Interactive approaches to second language reading. Cambridge: Cambridge University Press, 1998. p. 114-124.

COHEN, J. Statistical Power Analysis for the Behavioral Sciences. Hillsdale: Erlbaum, 1988.

DAVIES, F. Introducing reading. London: Penguin Group, 1995.

HASHEMI, A.; MOBINI, F.; KARIMKHANLOOIE, G. The Impact of Content-based Prereading Activities on Iranian High School EFL Learners' Reading Comprehension. Journal of Language Teaching and Research, v. 7, n. 1, p. 137-145, jan. 2016.

HUDSON, T. The effects of induced schemata on the "short circuit" in L2 reading: Nondecoding factors in L2 reading performance. In: CARRELL, P. L.; DEVINE, J.; ESKEY, D. E. Interactive approaches to second language reading. Cambridge: Cambridge University Press, 1998. p. 183-205.

JAHANGARD, A.; MOINZADEH, A.; KARIMI, A. The Effect of Grammar vs. Vocabulary Pre-teaching on EFL Learners' Reading Comprehension: a schema-theoretic view of reading. Journal of English Language Teaching and Learning, n. 8, p. 91-113, 2011.

LEVINE, A.; REVES, T. The four-dimensional model: Interaction of schemata in the process of FL reading comprehension. TESL Canada Journal, v. 2, n. 11, p.71-84, 1994.

MAUNSELL, M. Academic Pre-reading Activity Menus to Support International ESL Students in Higher Education. The Catesol Journal, v. 31, n. 1, p. 1-12, 2019.

MIHARA, K. Effects of pre-reading strategies on EFL/ESL reading comprehension. TESL Canada Journal, v. 2, n. 28, p.51-73, 2011. 
MOGHADDAM, N. N.; MAHMOUDI, A. The Effect of Pre-reading Activities on Reading Comprehension of Iranian EFL Learners. Advances in Language and Literary Studies, v. 3, n. 7, p. 235-242, jun. 2016.

MOHAMMADI, M.; MOENIKIA, M.; ZAHED-BABELAN, A. The role of advance organizer on English language learning as a second language. Procedia: Social and Behavioral Sciences, v. 2, n. 2, p.4667-4671, 2010.

MOORE, D. W.; READANCE, J. E.; RICKELMAN, R. J. Pre-reading activities for content area reading and learning. 2. ed. Newark, Delaware: International Reading Association, 1999.

ROSCIOLI, D. C. The relationship between technical high school Brazilian students' working memory capacity, pre-reading activities, and inference generation in reading comprehension in L2. 2017. 470 f. Tese (Doutorado em Inglês) - Programa de PósGraduação em Inglês, Universidade Federal de Santa Catarina, Florianópolis, 2017.

RUMELHART, D. E. Schemata: The building blocks of cognition. In: SPIRO, R. J. et al. Theoretical issues in reading comprehension. Hillsdale: Lawrence Erlbaum Associates, 1980.

TOMITCH, L. M. B. An analysis of the potential selection strategies which may determine the contents of the short-term, working memory system. Mimeo, UFSC, Florianópolis, 1990.

TOMITCH, L. M. B. Schema activation and text comprehension. Fragmentos, v. 2, n. 3, p. 29-43, 1991.

TOMITCH, L. M. B. Reading: Text organization, perception, and working memory capacity. 7. ed. Florianópolis: Pós-Graduação em Inglês - UFSC, 2003. (Advanced Research in English Series).

\section{About the authors}

Tatiana Koerich Rondon (https://orcid.org/0000-0002-7473-5267 )

$\mathrm{PhD}$ student in Applied Linguistics at the English Graduate Program, Federal University of Santa Catarina, Brazil. Holds a master's degree in English.

Lêda Maria Braga Tomitch (https://orcid.org/0000-0003-4183-8072)

Full Professor at the Foreign Languages Department, Federal University of Santa Catarina. Holds a PhD degree in English.

Recebido em agosto de 2020.

Aprovado em dezembro de 2020. 